\title{
Giant cell arteritis: difficult decisions in diagnosis, investigation and treatment
}

\author{
Elisabeth W. Paice
}

Department of Rheumatism and Rehabilitation, St Mary's Wing, Whittington Hospital, Highgate Hill, London N19 5NF, UK.

\section{Introduction}

It is nearly 100 years since Hutchinson described the case of an elderly man unable to wear his hat because of tenderness of his temporal arteries. ' Since then giant cell arteritis (GCA) has been much described, discussed, and, with the advent of corticosteroids, effectively treated. Although common enough for most doctors to be familiar with the typical features of headache, temporal artery inflammation, visual disturbance and polymyalgia rheumatica (PMR), it is sufficiently uncommon for atypical cases to continue to give rise to diagnostic difficulty. There are several areas of controversy in this condition, including the role of the erythrocyte sedimentation rate (ESR) in diagnosis and management, and indications for temporal artery biopsy. The right dose of corticosteroid is also questioned, the optimum duration of therapy, and the best alternative if corticosteroids are not tolerated in an adequate dose to control symptoms.

\section{Diagnostic difficulties}

Difficulties arise when the presenting feature is an unusual one, such as cough or claudication, and the physician, not suspecting GCA, fails to elicit other signs or symptoms which would point to the correct diagnosis. Equally difficult are those cases where the presenting feature is a classic one for GCA, such as headache, but the patient denies any associated symptoms to confirm the suspicion. Most difficult of all is the patient presenting with an isolated and atypical feature.

Ophthalmic complications are not restricted to sudden blindness. Amaurosis fugax, scintillating scotomata and diplopia may also occur, and may herald blindness. Furthermore when one eye goes blind, the other follows in $30 \%$ of cases, and usually within the next 7 days. ${ }^{2,3}$ Since treatment rarely

Correspondence: E.W. Paice, F.R.C.P.

Received: 13 March 1989 reverses established blindness, it is important to make a rapid diagnosis of GCA, and institute appropriate treatment at once.

Neurological complications may be similarly devastating and progressive. Transient ischaemic attacks, stroke, dementia and coma have all been described. ${ }^{4.5}$ Such neurological conditions are common amongst the elderly, and can easily be interpreted as arteriosclerotic. The possibility of GCA as the explanation for a sudden central nervous system syndrome in the elderly should always be borne in mind and steps taken to confirm or exclude the diagnosis as a matter of urgency.

Less common, and also less well recognized, are the respiratory manifestations of GCA. Cough is the commonest respiratory symptom, occurring in an estimated $9 \%$, usually developing with other features of GCA, though occasionally preceding them by a matter of months. It may be dry or productive of white or yellow sputum. Sore throat, diffusely felt across the anterior neck, without abnormality in the fauces, has also been noted. ${ }^{6}$ Severe lung arteritis with pulmonary infiltration or nodules occurs rarely, but may be fatal. The diagnosis may be made by discovering evidence of arteritis elsewhere, by transbronchial biopsy, or at post-mortem, when large or medium sized arteries may reveal the typical changes of GCA. ${ }^{7-9}$

Large vessel GCA usually presents with claudication of the arms or legs. Bruits over major vessels, absence of pulses, and absence of blood pressure are found on examination. ${ }^{10}$ Although limb claudication was the presenting feature in only $5 \%$ of cases in one series of patients with GCA $^{11}$ large artery involvement is detected clinically in $14 \%$ of cases and at post-mortem examination $64 \%$ of cases showed signs of femoral artery involvement. Aortic valve insufficiency and acute aortic dissection or rupture may occur. ${ }^{12}$ It may be difficult to decide whether an elderly patient with claudication and vascular bruits has GCA or arteriosclerosis. Doppler ultrasonography or angiography can help to differentiate, arteritis being typified 
by a smooth tapering and atheroma by irregular plaques. ${ }^{10}$ Temporal artery biopsy is usually but not invariably positive. ${ }^{12}$

Perhaps the most difficult diagnosis to make is that of GCA with constitutional symptoms alone. Nine elderly patients were reported who were extensively investigated for anaemia, weight loss, fever and general malaise associated with a raised ESR. ${ }^{13}$ All were thought to have an occult malignancy or some type of connective tissue disorder. Finally GCA was considered in each case. Of four who underwent temporal artery biopsy, two were positive. All were treated with corticosteroids, all responded fully, and all remained well over a 6-year follow-up period. In another series of 74 consecutive patients with biopsy proven GCA, the presenting complaint was fever in 12 and weight loss or anorexia in $7 .^{14}$ The finding of a raised ESR and frequently also a raised alkaline phosphatase may encourage a search for occult malignancy. Such expensive and invasive investigations as marrow or lumbar puncture, liver biopsy, arteriography, barium studies or even laparotomy are performed before a temporal artery biopsy is considered. ${ }^{15}$

If a radioisotope bone scan is included in the work up for malignancy, a clue to the diagnosis of GCA may be revealed. In PMR, with or without GCA, radioisotope bone scans are frequently abnormal, with increased uptake particularly over the sternoclavicular, shoulder, and elbow joints, in a symmetrical distribution quite unlike that of disseminated malignancy. ${ }^{16}$ In two cases, ${ }^{17}$ the previously unsuspected diagnosis of GCA was made when calcification of the temporal arteries was detected on CT scan of the brain performed for the investigation of headache. Occasionally, in the investigation of a patient with constitutional symptoms alone, it is not possible to prove the diagnosis histologically, either because the temporal artery biopsy is negative or because it cannot be performed. The idea of using corticosteroids as a therapeutic trial in such instances is regarded by some with distaste, but it may be the only way of confirming the diagnosis and restoring an elderly person to a reasonable quality of life. A puritanical insistence on histological proof before treatment is both unrealistic and unkind.

\section{Investigation}

An unexpectedly high ESR may be the first clue to the diagnosis of GCA in a difficult case. Unfortunately the ESR is not invariably raised in clinically florid cases. Values of less than $30 \mathrm{~mm} /$ hour (Westergren) were found in $22.5 \%$ of 80 untreated patients with clinical evidence of PMR or GCA. ${ }^{18}$ The height of the ESR is not a predictor for the severity of the disease ${ }^{19}$ and serious complications have occurred in patients with a normal ESR. Some elderly people have a raised ESR in any event, without an identifiable cause, ${ }^{20}$ and a modestly raised ESR is likely to be ignored because it falls into the 'age adjusted' normal range. Of 36 patients with biopsy-proven GCA and 'normal' age adjusted ESR, 16 had an ESR of $21-40 \mathrm{~mm} /$ hour. ${ }^{21}$

The fact that the elderly may have an elevated ESR for which no cause can be found does not mean that the ESR will necessarily be any higher in those who do have an identifiable disease. The acceptance of the concept of an age adjusted normal ESR may blunt us to the clues offered by a mild elevation in the presence of suspicious symptoms. The ESR usually falls with treatment, but the response can be slow, with normal values reached after 2-4 weeks. $C$ reactive protein (CRP) has been shown to be more responsive in terms of rapid fall with treatment and rise with clinical relapse than the ESR. ${ }^{22-24}$ It has therefore been suggested that the ESR be abandoned in favour of CRP for monitoring the response to treatment. It might be more reasonable to use clinical evidence of relapse as the guide, relying on these tests only to lend support to clinical judgement. It has not been shown that CRP is superior to ESR in screening for GCA. The CRP has been normal in a patient with clinically obvious GCA and a high ESR. ${ }^{25}$

A temporal artery biopsy showing giant cells in the media is the cornerstone of diagnosis in GCA. In 2 study of 134 biopsies for suspected GCA,${ }^{26} 46$ were positive and 88 negative. Of the negative biopsies only 8 developed clinical evidence of GCA. The biopsy correctly predicted the need for corticosteroid therapy in $94 \%$ of cases. In a similar analysis of 103 biopsies only 10 of 58 patients with negative biopsies had subsequent definite clinical evidence of GCA. ${ }^{27}$ Such classic symptoms as jaw claudication, headache and physical abnormalities of the temporal arteries are much more common in patients with positive biopsies. In fact it is doubtful whether it is worthwhile performing the biopsy when the clinical picture is either of pure PMR or obvious GCA. When the clinical picture is less clear, as with a sudden ophthalmic or neurological disturbance, a biopsy is more likely to influence management. In such cases a single negative biopsy may not be sufficiently reassuring, and a biopsy of the other side may be considered. Eighty six per cent of positive biopsies are obtained on the first side sampled, and only $14 \%$ from a second sample. ${ }^{28}$ Once steroid treatment has been started the chances of getting a positive biopsy fall off with every day that passes. In a study of 132 patients with clinical evidence of GCA, 84 had a positive biopsy. Of these, $82 \%$ of those biopsied before starting corticosteroids were positive, $60 \%$ of those biopsied within one week of starting treatment, and only $10 \%$ of those biopsied later. ${ }^{29}$ 


\section{Treatment}

The mainstay of treatment for GCA is corticosteroid therapy, but there is some controversy over the optimum dose and duration of treatment. Two recent studies have addressed this question and are worth considering in some detail. Delecoeuillerie et al. reviewed the case notes of patients diagnosed as having PMR or GCA in one French hospital over the period 1976 to $1986 .^{30}$ One hundred and thirty two patients were identified who had clinically pure PMR and 78 who had clinical evidence of GCA. The influence of starting dose of corticosteroid on the prognosis and the development of steroid related side effects was studied. In the pure PMR group doses of $15-30 \mathrm{mg}$ daily were associated with more side effects than doses of 7-12 mg daily, without any detectable benefit in terms of prognosis. Nine of these PMR patients later developed symptoms of GCA, but this was not related to the starting dose of prednisolone. In the GCA group, patients treated with low starting doses of prednisolone (10-20 mg/day) developed fewer corticosteroid side effects and had no more visual or neurological complications than patients starting on higher doses (21-60 mg/day). The authors conclude that high doses of steroid (above $12 \mathrm{mg}$ ) are of no value in PMR and that the value of high doses (above $20 \mathrm{mg} /$ day) for GCA is doubtful. They admit several flaws in the study, however. Because the study was retrospective there was no randomization of start dose and, not surprisingly, all the GCA patients with visual disturbance at the time of diagnosis were given the high starting doses. Possibly they would have done less well on a lower dose. Any patient not responding to the starting dose within 48 hours was given an increased dose, but was not considered to have left the original group. How many patients needed the increased dose is not revealed, but again these patients might not have done so well without it. The incidence of corticosteroid related side effects, such as diabetes or crush fractures was not compared with the expected incidence in an age matched population.

The second study was carried out by Andersson et $a l$. in two Swedish hospitals. ${ }^{31,32}$ The records of all the 90 patients diagnosed as having GCA between 1968 and 1975 were studied and survivors traced $9-16$ years from the time of the original diagnosis. Sixty five of the patients had biopsy proven GCA and the remainder fulfilled the criteria for PMR. The authors considered the starting dose of prednisolone, the duration of treatment, the incidence of steroid related side effects and the mortality rate. The mean initial dose of prednisolone was $33.2 \mathrm{mg}$ and the mean duration of therapy was 5.8 years. Attempts to withdraw therapy resulted in a relapse in nearly half the cases regardless of the time after diagnosis that the attempt was made, and regardless of whether the patient had PMR or
GCA. The 43 patients who died during the follow-up period had a mean age of 82.5 years at time of death. A note was made of other conditions developing after the diagnosis of PMR or GCA. Some of these conditions, such as fractured neck of femur ( 9 cases), vertebral collapse ( 3 cases) and diabetes (10 cases) might be considered to be caused by steroid therapy. However, comparison with population studies in Sweden showed that none of these conditions had occurred with greater frequency in the patients than in the general population in this age group. The mortality rate for the patients 5 years after diagnosis was slightly better than expected for the general population. After 10 and 15 years the observed mortality equalled that expected. The authors therefore concluded that it was often necessary to continue with a modest dose of corticosteroid for years but that a mean starting dose of $33.2 \mathrm{mg}$ was compatible with a normal life expectancy without an excess of steroid related side effects.

A reasonable conclusion to draw from these studies might be that modest doses of $15 \mathrm{mg}$ or less will be adequate for most cases of PMR, and doses of $20-40 \mathrm{mg}$ for most cases of GCA. There is insufficient evidence about the outcome of patients presenting with visual, neurological or large vessel arteritis and treated with doses of less than $40 \mathrm{mg}$. Most authorities? quote a recommended dose of $40-60 \mathrm{mg} /$ day for this group, reducing to lower maintenance doses within a few weeks. The intention should be to withdrawe treatment over a 2 year period for PMR and over $3-5 \stackrel{+}{.}$ years for GCA.

The timing of steroid doses can have an influence both on efficacy and side effects. In a prospective study, Hunder et al. ${ }^{32}$ tried three different dosage regimes on 60 consecutive patients with GCA. Group A were given $15 \mathrm{mg}$ 8-hourly; Group B were given $45 \mathrm{mg}$ every morning; Group $\mathrm{C}$ were given $90 \mathrm{mg}$ on alternate mornings. At the end of 4 weeks the results were as follows: in Group A 18/20 were in remission, but 9 patients had evidence of steroid related side effects; in Group B 16/20 were in remission and 7 had side effects; in Group C only 6/20 were in remission, and no side effects were noted. Subsequently 4 patients were treated with $120 \mathrm{mg}$ of prednisolone on alternate days without achieving remission in 4 weeks. Divided doses are both more effective and more toxic; alternate day regimens are ineffective.

The duration of therapy for GCA must depend on the patient's symptoms, or on other evidence of continued activity, such as raised ESR or CRP. The mean seems to be about three years. ${ }^{34,35}$ Although the relapse rate is high when steroids are withdrawn completely, a low maintenance dose keeps the disease at bay. An increased mortality was found where the maintenance dose remained over $10 \mathrm{mg}^{36}$

Although nonsteroidal anti-inflammatory drugs have some effect on the muscular pain and stiffness of 
PMR, it is less dramatic or complete than that of corticosteroids and there is no evidence that these drugs are effective for GCA. ${ }^{37}$ Nonsteroidal antiinflammatory drugs may be tried for those patients with clinically pure PMR and some relative contraindication to corticosteroids. They are also useful when withdrawal of the last few milligrams of prednisolone proves difficult because of the unmasking of osteoarthritic pains. Local injection of steroid to the sternoclavicular, acromioclavicular or shoulder joints may be helpful when one of these joints continues to give symptoms despite an overall improvement with systemic treatment.

Occasionally a patient fails to respond even to high doses of steroid, or the side effects become intolerable. $\stackrel{2}{3}$ Azathioprine has been studied ${ }^{38}$ in a one year con- $\stackrel{\mathbb{Q}}{\mathcal{Q}}$ trolled trial to ascertain if there is a steroid sparing.. effect. A dose of $150 \mathrm{mg}$ daily was compared with $\vec{F}$ placebo in a series of 31 patients with PMR or GCA, stabilized on a minimum effective dose of prednisolone. Only 10 patients on azathioprine completed $\frac{\overline{\bar{N}}}{\bar{N}}$ 36 weeks on the drug because of gastrointestinal $\frac{\text { }}{\sigma}$ disturbance. The role of azathioprine is therefore still $\stackrel{\Phi}{\varrho}$ unclear but perhaps a lower dose in these elderly ${ }^{\circ}$ patients would be better tolerated and still be effective. $\vec{\circ}$ Dapsone, ${ }^{39}$ methotrexate, cyclophosphamide and cyclosporine $^{40}$ have all been tried in the resistant or $\vec{\omega}$ difficult case. ${ }^{41}$

\section{References}

1. Hutchinson, J. Disease of the arteries. On a peculiar form of thrombotic arteritis of the aged which is sometimes productive of gangrene. Arch Surg 1890, 1: 323-329.

2. Jonasson, F., Cullen, J.F. \& Elton, P.A. Temporal arteritis. Scott Med J 1979, 24: 111.

3. Kearns, P. Temporal artery biopsy. Br Med J 1988, 297: 1404.

4. Caselli, R.J., Hunder, G.G. \& Whisnant, J.P. Neurologic disease in biopsy proven giant cell (temporal) arteritis. Neurology 1988, 38: 352-359.

5. Lipton, R.B., Rosenbaum, D. \& Mehler, M.F. Giant cell arteritis causes recurrent posterior circulation transient ischaemic attacks which respond to corticosteroid. Eur Neurol 1987, 27: 97-100.

6. Larson, T.S., Hall, S., Hepper, N.G.G. \& Hunder, G.G. Respiratory tract symptoms as a clue to giant cell arteritis. Ann Int Med 1984, 101: 594-597.

7. Karam, G.H. \& Fulmer, J.D. Giant cell arteritis presenting as interstitial lung disease. Chest 1982, 82: 781-784.

8. Kramer, M.R., Melzer, E., Nesher, G. \& Sonnenblick, M. Pulmonary manifestations of temporal arteritis. Eur $J$ Respir Dis 1987, 71: 430-433.

9. Ladanzi, M. \& Fraser, R.S. Pulmonary involvement in giant cell arteritis. Arch Pathol Lab Med 1987, 111: $1178-1180$.

10. Perruquet, J.L., Duane, E.D. \& Harrington, T.M. Aortic arch arteritis in the elderly. An important manifestation of giant cell arteritis. Arch Intern Med 1986, 146: 289-291.

11. Greene, G.M. Giant cell arteritis of the legs. Clinical isolation of severe disease with gangrene and amputation. Am J Med 1986, 81: 727-733.

12. Klein, R.G., Hunder, G.G., Stanson, A.W. \& Sheps, S.G. Large artery involvement in giant cell (temporal) arteritis. Ann Int Med 1975, 823: 806-812.

13. Allison, M.C. \& Gough, K.R. Steroid sensitive systemic disease with anaemia in the elderly: a manifestation of giant cell arteritis? Postgrad Med J 1985, 61: 501-503.

14. Healey, L.A. \& Wilske, K.R. Presentation of occult giant cell arteritis. Arthritis Rheum 1980, 23: 641-643.

15. Strachan, R.W., How, J. \& Bewsher, P.D. Masked giant cell arteritis. Lancet 1980, i: 194.

16. Paice, E.W., Wright, F.W. \& Hill, A.G.S. Sternoclavicular erosions in polymyalgia rheumatica. Ann Rheum Dis 1983, 42: 379-383.

17. Karacostas, D., Taskos, N., Tsounis, S. \& Nicolaides, T. $\overrightarrow{-}$ CT findings in temporal arteritis. A report of 2 cases. Neuroradiology 1986, 28: 373.

18. Ellis, M.E. \& Ralston, S. The ESR in the diagnosis ard management of the polymyalgia rheumatica/giant cell arteritis syndrome. Ann Rheum Dis 1983, 42: 168-179 $\vec{\varphi}$

19. Jacobson, D.M. \& Slamovits, T.L. Erythrocyte sedime 0 tation rate and its relationship to haematocrit in gia cell arteritis. Arch Ophthalmol 1987, 105: 965-967. .

20. Boyd, R.V. \& Hoffbrand, B.I. Erythrocyte sedimentation rate in elderly hospital inpatients. Br Med J 1966, 1: 901-902.

21. Wong, R.L. \& Korn, J.H. Temporal arteritis without an elevated erythrocyte sedimentation rate. Am J Med 1986, 80: 959-964.

22. Mallya, R.K., Hind, C.R., Berry, H. \& Pepys, M.B. Serum $C$ reactive protein in polymyalgia rheumatica. A prospective serial study. Arthritis Rheum 1985, 28: 383-387.

23. Andersson, R., Malmvall, B.-E. \& Bengtsson, B.-A. Acute phase reactants in initial phase of giant cell arteritis. Acta Med Scand 1986, 220: 365-367.

24. Schreiber, $S$. $C$ reactive protein in the management of polymyalgia rheumatica and giant cell arteritis. Clin Rheumatol 1987, 6: 97-98.

25. Eshagen, J. \& Goeken, J.A. C reactive protein in giant cell (cranial, temporal) arteritis. Ophthalmology 1980, 87: $1160-1166$.

26. Hall, S., Persellin, S., Lie, T.J., O’Brien, P.C., Kurland, L.T. \& Hunder, G.G. The therapeutic impact of temporal artery biopsy. Lancet 1983, ii: 1217-1220.

27. Vilaseca, J. Clinical usefulness of temporal artery biopsy. Ann Rheum Dis 1987, 46: 282-285.

28. Hall, S. \& Hunder, G.G. Is temporal artery biopsy prudent? Mayo Clin Proc 1984, 59: 793-796.

29. Allison, M.C. \& Gallagher, P.J. Temporal artery biopsy and corticosteroid treatment. Ann Rheum Dis 1984, 43: 416-417. 
30. Delecoeullerie, G., Joly, P., Cohen de Lara, A. \& Paolaggi, J.B. Polymyalgia rheumatica and temporal arteritis: a retrospective analysis of prognostic features and different corticosteroid regimens. Ann Rheum Dis 1988, 47: 733-739.

31. Andersson, R., Malmvall, B.-E. \& Bengtsson, B.-A. Long term survival in giant cell arteritis including temporal arteritis and polymyalgia rheumatica. Acta Med Scand 1986, 220: 361-364.

32. Andersson, R., Malmvall, B.-E. \& Bengtsson, B.-A. Long term corticosteroid treatment in giant cell arteritis. Acta Med Scand 1986, 220: 465-469.

33. Hunder, G.G., Sheps, S.G., Allen, G.L. \& Joyce, J.W. Daily and alternate day corticosteroid regimens in treatment of giant cell arteritis. Ann Int Med 1975, 82: 613-618.

34. Behn, A.R., Perera, T. \& Myles, A.B. Polymyalgia rheumatica and corticosteroids. How much for how long? Ann Rheum Dis 1983, 42: 374-378.

35. Wilske, K.R. \& Healey, L.A. Polymyalgia rheumatica and giant cell arteritis. The dilemma of therapy. Postgrad Med 1985, 77: 243-248.
36. Graham, E., Holland, A., Avery, A. \& Russel, R.W.R. Prognosis in giant cell arteritis. $\mathrm{Br} \mathrm{Med} J$ 1981, 282: 269-271.

37. Chuang, T.Y., Hunder, G.G., Ilstrup, D.M. \& Kurland, L.T. Polymyalgia rheumatica. A 10 year epidemiological os clinical study. Ann Int Med 1982, 97: 672-680.

38. De Silva, M. \& Hazleman, B.L. Azathioprine in giant cell arteritis/polymyalgia rheumatica. A double blind study. Ann Rheum Dis 1986, 45: 136-138.

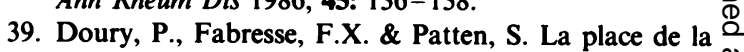
dapsone dans le traitement de la maladie de Horton et de la pseudopolyarthrite rhizomelique. Ann Med Interne $\vec{\circ}$ (Paris) 1984, 135: 31-35.

40. Wendling, D., Hory, D. \& Blanc, D. Cyclosporine: a new adjuvant therapy for giant cell arteritis? Arthritis Rheum 1985, 28: 1078-1079.

41. Olhagen, B. Polymyalgia rheumatica. Clin Rheum Dis 1986, 12: 33-47. 